\title{
Robustness and Disturbance Rejection of PD/H- $\infty$ Integrated Controller for Flexible Link Manipulator System
}

\author{
E. A. Alandoli*, M. Sulaiman and M. Z. A. Rashid \\ Center for Robotics and Industrial Automation, Faculty of Electrical Engineering, Universiti Teknikal Malaysia Melaka (UTeM), Hang \\ Tuah Jaya, 76100 Durian Tunggal, Melaka, Malaysia
}

Received 5 March 2018; Accepted 20 February 2019

\begin{abstract}
Due to the significant advantages of flexible link manipulators (FLMs) and the high demand for developing a robust controller in order to perform fast and accurate operations, this research proposes the $\mathrm{PD} / \mathrm{H}-\infty$ integrated controller for the purpose of position tracking and vibration suppression of a FLM system and verifies its robustness by utilizing longer lengths and test the proposed controller under a disturbance. The $\mathrm{PD} / \mathrm{H}-\infty$ integrated controller was compared with the Linear quadratic regulator (LQR) controller in terms of position tracking and vibration suppression for the lengths of 50 $\mathrm{cm}, 75 \mathrm{~cm}$ and $100 \mathrm{~cm}$, then the controllers were assessed under a disturbance for the three lengths of the FLM system. The $\mathrm{PD} / \mathrm{H}-\infty$ integrated controller has shown higher capability to control longer lengths and to reject a disturbance than the LQR controller which has been verified via simulation using MATLAB/Simulink software.
\end{abstract}

Keywords: flexible link manipulator, $\mathrm{PD} / H$ - $\infty$ integrated controller, robustness and disturbance rejection

\section{Introduction}

Due to the demand of saving energy and provide fast speed of operations in order to move and manipulate objects on workspaces, FLMs are highly required to be used in robotics instead of rigid link manipulators (RLMs) [1]. Conventional robots' manipulators are designed to be rigid and have high stiffness in order to reduce vibration and perform accurate operations with utilizing simple controller schemes. These robotic manipulators require big actuators size which lead to higher energy consumption and lower speed [2]. There are several advantages of FLMs compared to RLMs like; FLMs need smaller size actuators which leads to lower energy consumption, less materials, faster response, and less cost [3]-[4]. Besides that, FLMs require less maintenance and have lower inertia [5]. FLMs receive high attention in research due to their advantages which are important in different applications such as medical robots and light robots like space arm manipulators as reported by the study in [6], used in nuclear plant, martial activities, agriculture sectors and homecare [5]. Additionally, FLMs are considered safer than RLMs in order to be operated near to humans [7]. According to the study in [8], manufacturing industries use flexible systems in order to keep the manufacturing industries competitive, reduce the expenses of hardware, and to enable an enterprise to produce closer to requirements.

Many hybrid and integrated controllers were designed in order to ensure the robustness of the control schemes and to stabilize FLM systems in terms of position tracking and vibration suppression. A strategy of two stages control was

*E-mail address: alandolie@yahoo.com

ISSN: 1791-2377 @ 2019 Eastern Macedonia and Thrace Institute of Technology. All rights reserved. doi:10.25103/jestr.121.04 proposed in[9], a model based joint controller was used for position tracking and an impedance controller to suppress the vibration at the tip point of FLMs. Even this control strategy is robust, it can't consider the flexibility influence once the FLM moves from the initial to the targeted position. Rigid-Flexible manipulators were controlled by a method of trajectory planning in order to reduce the deflection of the tip of the FLM as mentioned by[10]which is required to reach the desired destination with minimum error. Also in [11] employed a time optimal trajectory planning for flexible link robot. However, the trajectory planning method is restricted to a certain path.

An inversion-based control was developed for rest to rest movement of Multi-FLMs, the problem of this method is that the fast response of a joint generates more oscillations at the tip of the FLMs and in order to minimize the tip deflection a planning trajectory is needed which constrains the system[12]. In [13], an adaptive impedance controller for two-FLMs system was designed and compared with nonadaptive impedance controller. Although the performance of the adaptive impedance controller is better than the nonadaptive impedance controller, the controller response is slow with more vibration which may generate much more vibration in case the system is faster.

Lookup table control method was applied with using positive position feedback in [14], this controller can optimally tune its parameters by itself for maximum response of the system. However, using positive position feedback increases the flexibility of the FLM which results larger steady state error. The authors in [15] utilized Bacteria Foraging Optimization (BFO) with Genetic Algorithm (GA) to optimally tune PD controller parameters in order to control the tip position of two-FLMs. The performance of the parameters obtained by BFO is better than GA in terms of position tracking and vibration suppression, but also BFO performance needs to be improved more. 
The study in [16]developed a hybrid controller of PDFuzzy logic controller (FLC), the hybrid controller was optimized by GA method in order to optimize the rule base of FLC. The performance of the hybrid controller is satisfactory in terms of the position tracking, but the vibration need to be more reduced which a GA-based multimodal command shaper was augmented with FLC in order to minimize the vibration at the expense of position tracking response. Numerical optimization was used in [17]to design gain-scheduled strictly positive real controller for position tracking and vibration suppression of two-FLMs. A modelbased predictive controller (MPC) was proposed in[18]for reference trajectory and vibration suppression of a FLM. The results show that the MPC strategy to suppress the vibration is not enough capable to eliminate the oscillations.

A mixed sensitivity $H_{2} / H_{\infty}$ controller was proposed in [19] and designed based on linear matrix inequality (LMI) technique. The mixed controller has satisfactory performance for the position tracking and vibration suppression. However, designing and implementing such controller are complicated. Another integrated controller was developed in [20], the controller consists of a resonant controller as the inner loop feedback to control the vibration based on the resonant frequencies and a FLC as the outer loop feedback for position tracking of the FLM system with payload. The proposed controller showed good ability to track the FLM and to suppress its vibration, but the increment of overshoot, rise time, settling time, and vibration are noticeable with increasing the payload.

PD feedback controller based on Lyapunov method was investigated in [21] for position tracking of a FLM with employing piezoelectric (PZT) actuators which can produce a shear force opposite the FLM's deflection in order to damp the vibration. The PD feedback controller performance needs more improvement and PZT actuators were used for damping vibrations need to verify the optimal location along the FLM during the experimental work for getting better vibration suppression. After that, the authors in [22]used combined scheme of PD-based hub motion control to track the FLM system and utilized PZT actuators to suppress the vibration. However, the system response is very slow and the oscillations of the FLM's tip require many PZT actuators to be bonded along the FLM in order to suppress the vibration in less time, but increasing the number of PZT actuators affects the flexibility of the FLM and increases its total mass.

Control scheme consists of two stages was developed in [7], the first stage is mainly for position tracking of the system, and the second stage damps the vibration by employing PZT actuators. The experimental and simulation results show that PZT is effective to reduce the steady state error of position and to damp the vibrations, moreover the system reaches its steady state in less time needed for traditional controls, but PZT actuators require high voltage and expensive amplifier and interfacing circuits. More types of controllers have been used to control FLMs are reviewed in [23].

This research aims to propose the $\mathrm{PD} / H-\infty$ integrated controller for position tracking and vibration suppression of FLM system, the robustness of the proposed controller is verified in terms of controlling longer links of the FLM and disturbance rejection compared to the standard LQR controller. The remaining of this paper is organized as follows: the methodology, the system description, the controllers' design, the method of performance analysis, the results and discussion, and the article conclusion.

\section{Methodology}

This research is to assess the robustness of $\mathrm{PD} / H-\infty$ integrated controller for the purpose of position tracking and vibration suppression for single FLM under a disturbance and using different lengths. When the FLM system moves at certain direction and then stop, FLM will vibrate and take certain period of time to settle down, also the vibrations increase by increasing the system response. Thus, the aim of this work is to ensure when the FLM system stop the vibrations can be rapidly minimized even that the system response is faster and disturbed.

This work is simulation using MATLAB/Simulink. The system consists of a servomotor as an actuator and the flexible link as a subject of study. The FLM system is shown in Fig.1. The angle $\theta(t)$ presents the desired position and $\propto(t)$ presents the deflection of the FLM which need to be reduced as shown in Fig.2 by utilizing the proposed controller.



Fig.1. FLM system

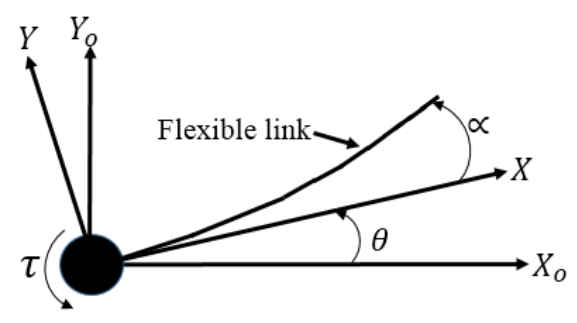

Fig. 2. Schematic of FLM system

\section{System Model}

The system mathematical model is expressed in Eq.1 and Eq. 2 in state space form which has been derived by the authors in [22] using Euler-Lagrange's equations.

$$
\begin{aligned}
& X^{\cdot}=A X+B u \\
& y=C X
\end{aligned}
$$

where:

$$
\begin{aligned}
A & =\left[\begin{array}{cccc}
0 & 0 & 1 & 0 \\
0 & 0 & 0 & 1 \\
0 & \frac{k_{s}}{J_{e q}} & \frac{-\eta_{m} \eta_{g} k_{t} k_{m} k_{g}^{2}-B_{e q} R_{m}}{J_{e q} R_{m}} & 0 \\
0 & \frac{-k_{s}\left(J_{e q}+J_{l i n k}\right)}{J_{e q} J_{\text {link }}} & \frac{\eta_{m} \eta_{g} k_{t} k_{m} k_{g}^{2}+B_{e q} R_{m}}{J_{e q} R_{m}} & 0
\end{array}\right] \\
B & =\left[\begin{array}{c}
0 \\
0 \\
\frac{\eta_{m} \eta_{g} k_{t} k_{g}}{J_{e q} R_{m}} \\
\frac{-\eta_{m} \eta_{g} k_{t} k_{g}}{J_{e q} R_{m}}
\end{array}\right], C=\left[\begin{array}{llll}
1 & 1 & 0 & 0
\end{array}\right]
\end{aligned}
$$


Based on the system numerical values shown in Tab.1, the system mathematical model can be rewritten as shown in Eq.3 with the initial length of $50 \mathrm{~cm}$.

Table 1. Numerical values of the FLM system

\begin{tabular}{l|c|c}
\hline Symbol & Description & Value \\
\hline$B_{e q}$ & $\begin{array}{c}\text { High gear viscous } \\
\text { damping coefficient } \\
\text { Equivalent high gear } \\
J_{e q}\end{array}$ & $\begin{array}{c}0.004 \\
\text { (N.m.s } / \mathrm{rad})\end{array}$ \\
$\eta_{m}$ & $\begin{array}{c}\text { Monternal load } \\
\text { extertia without }\end{array}$ & $0.00208 \mathrm{~kg} \cdot \mathrm{m}^{2}$ \\
$\eta_{g}$ & Motor efficiency & 0.69 \\
$K_{m}$ & Gearbox efficiency & 0.90 \\
$K_{g}$ & Back-emf constant & 0.00768 \\
$K_{t}$ & High gear ratio & $(\mathrm{V} . \mathrm{s} / \mathrm{rad})$ \\
$R_{m}$ & Motor torque constant & $0.00767(\mathrm{~N} . \mathrm{m} / \mathrm{A})$ \\
$M$ & Motor armature resistance & $2.6 \Omega$ \\
$K_{s}$ & Mass of Flexible Link & $0.0549 \mathrm{~kg} / \mathrm{m}$ \\
\hline \multicolumn{2}{c}{ Stiffness constant } & 1.4 \\
\hline
\end{tabular}

$\left[\begin{array}{c}\dot{\theta} \\ \dot{\alpha} \\ \ddot{\theta} \\ \ddot{\alpha}\end{array}\right]=\left[\begin{array}{cccc}0 & 0 & 1 & 0 \\ 0 & 0 & 0 & 1 \\ 0 & 673.07 & -35.1667 & 0 \\ 0 & -1281.77 & 35.1667 & 0\end{array}\right]\left[\begin{array}{c}\theta \\ \alpha \\ \dot{\theta} \\ \dot{\alpha}\end{array}\right]+\left[\begin{array}{c}0 \\ 0 \\ 61.7325 \\ -61.7325\end{array}\right] V_{m}$

\section{LQR Controller Design}

The simplicity to design LQR and the straightforward to be used for multivariable system with the same procedure of design as for single-input-single-output system are the advantages of utilizing it in this research. The LQR controller gain matrix is presented by Eq.4 which can be obtained by solving Algebraic Riccati Equation (ARE) shown in Eq.5 as discussed by [24].

$\mathrm{K}=\mathrm{T}^{-1}\left(\mathrm{~T}^{\mathrm{T}}\right)^{-1} \mathrm{~B}^{\mathrm{T}} \mathrm{P}=\mathrm{R}^{-1} \mathrm{~B}^{\mathrm{T}} \mathrm{P}$

$\mathrm{A}^{\mathrm{T}} \mathbf{P}+\mathrm{PA}-\mathrm{PBR}^{-1} \mathrm{~B}^{\mathrm{T}} \mathrm{P}+\mathrm{Q}=\mathbf{O}$

ARE solution is represented by, $P$, and $Q$, is the weighting matrix defines the weights on the state while $R$ is the weighting matrix defines the weights on the input. The matrix, , plays important role on the system performance. Eq. 6 shows on how, , matrix can be manually tuned. The parameters' tuning of the matrix are on trial and error based on the system performance. Ref [25] has more details about tuning LQR controller. Fig. 3 shows LQR controller diagram which consists of the FLM system model and the LQR feedback gain matrix that is used in this study. $N$ is a gain to eliminate the steady state error and obtained by trial and error.

$Q=\left[\begin{array}{cccc}q_{1} & 0 & 0 & 0 \\ 0 & q_{2} & 0 & 0 \\ 0 & 0 & \vdots & 0 \\ 0 & 0 & 0 & q_{n}\end{array}\right]$
The LQR gain presented in Eq.7 produces the optimal performance of the system which is obtained by selecting the diagonal elements of $Q$ matrix $(300,300,0,0)$.

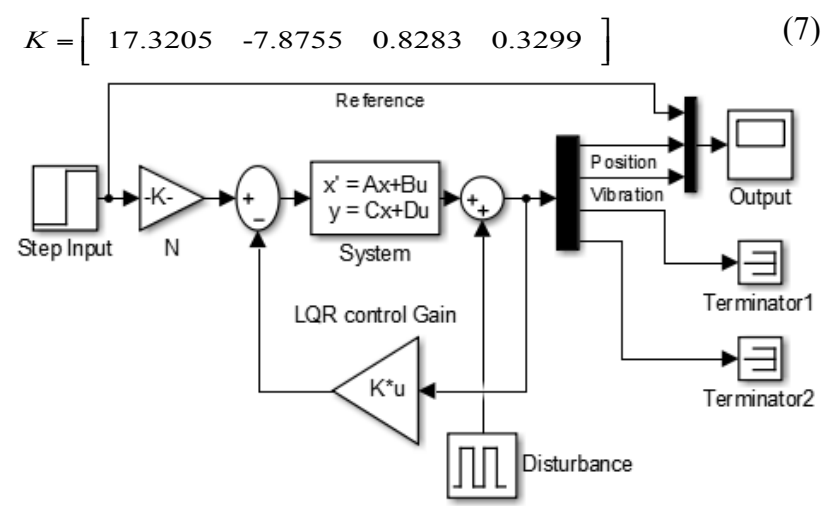

Fig. 3. LQR controller diagram

\section{PD/H- $\infty$ Integrated Controller Design}

The integrated controller proposed in this research is shown in Fig. 4 which is the proportional-derivative (PD) controller integrated with the standard $H-\infty$ controller. This proposed controller in this study depends on the capability of PD controller to improve the system transient response, its


effectively suppress the vibration, these features play an important role in this research work, meanwhile design a robust controller. $H-\infty$ controller is a robust controller has and several methods such as standard $H$ - $\infty$ controller, LMI and loop shaping method. However, LMI and loop shaping methods are quite complicated to be designed, so standard $H-\infty$ controller is selected to be integrated with PD controller in this research as it is easier for design.

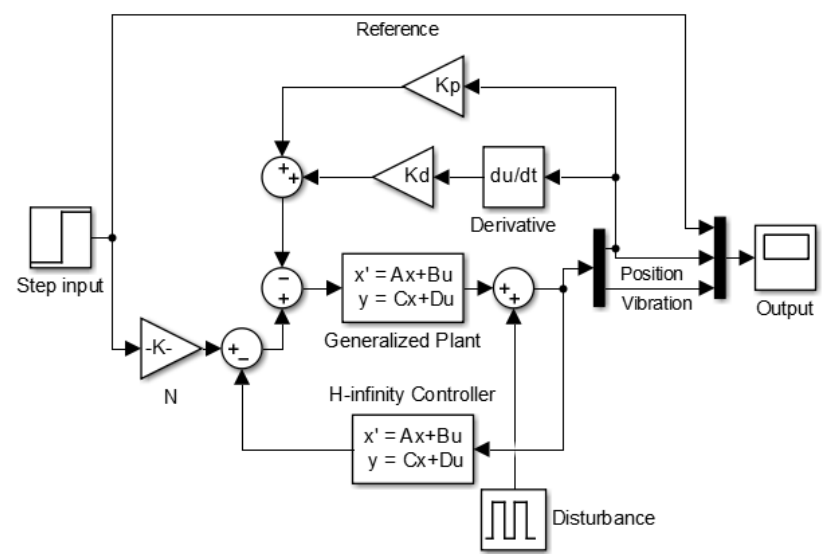

Fig. 4. $\mathrm{PD} / H-\infty$ integrated controller diagram

\subsection{PD Controller Tuning}

PD controller improves the system transient response, where this controller has two parameters, the proportional gain, $K_{p}$, and the derivative gain, $K_{d}$. The transfer function of PD controller is the sum of the proportional gain, $K_{p}$, and the derivative gain, $K_{d}$, multiplying by differentiated signal obtained as written in Eq.8 [26]. In this research, PD controller is manually tuned as the manual tuning method is easier and can obtain the optimal gains to produce the satisfactory performance. The parameters in Tab. 2 perform faster response for the system. 
$G_{c}=K_{p}+K_{d} s$

Table 2. PD controller parameters

\begin{tabular}{l|c|c}
\hline \multirow{2}{*}{ Tuning Method } & \multicolumn{2}{|c}{ PD Controller Parameters } \\
\cline { 2 - 3 } & $\boldsymbol{K}_{\boldsymbol{p}}$ & $\boldsymbol{K}_{\boldsymbol{d}}$ \\
\hline Manual Tuning & 100 & 2 \\
\hline
\end{tabular}

\subsection{H- $\infty$ Controller Design}

$H-\infty$ control system consists of a generalized plant $G(s)$ and a robust controller $K(s)$ as shown in Fig.5. The generalized plant $G(s)$ is elaborated in Eq.9.

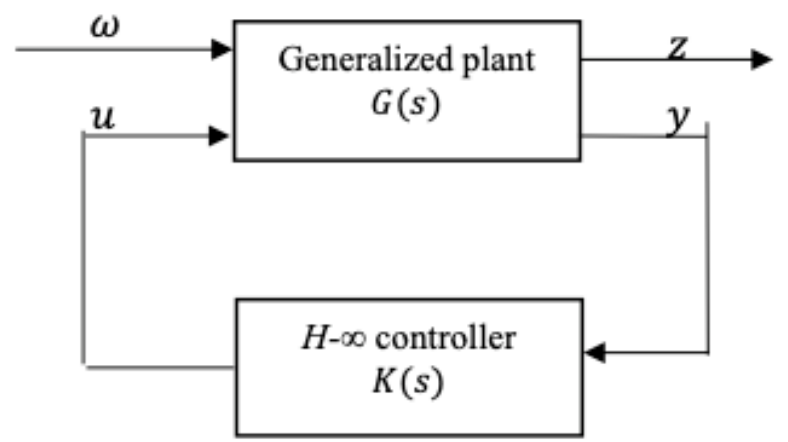

Fig.5. Standard $H-\infty$ control system

$$
\left[\begin{array}{l}
\dot{x} \\
z \\
y
\end{array}\right]=\left[\begin{array}{ccc}
A & B_{1} & B_{2} \\
C_{1} & D_{11} & D_{12} \\
C_{2} & D_{21} & D_{22}
\end{array}\right]\left[\begin{array}{c}
x \\
\omega \\
u
\end{array}\right]
$$

where $x$ is the state variable, $z$ is the evaluation signal, $y$ is the measured signal, $\omega$ is the exogenous input signal, and $u$ is the control input signal.

The standard $H-\infty$ controller is formulated in [27] as in Eq. 10 to Eq. 12 .

$$
K(s)=\text { LinearFractional Transformation }\left\{K_{c}, Q\right\}
$$

where:

$K_{c}=\left[\begin{array}{ccc}A^{*} & -Z L & Z B_{2}^{*}\left(D_{12}^{T} D_{12}\right)^{-1 / 2} \\ F & 0 & \left(D_{12}^{T} D_{12}\right)^{-1 / 2} \\ -\left(D_{21} D_{21}^{T}\right)^{-1 / 2} C_{2}^{*} & \left(D_{21} D_{21}^{T}\right)^{-1 / 2} & 0\end{array}\right]$

$A^{*}=A+B_{1} B_{1}^{T} X_{\infty}+B_{2} F+Z L C_{2}^{*}$

$B_{2}^{*}=B_{2}+Y_{\infty} C_{1}^{T} D_{12}$

$C_{2}^{*}=C_{2}+D_{21} B_{1}^{T} X_{\infty}$

$F=-D_{12}^{*} C_{1}-\left(D_{12}^{T} D_{12}\right)^{-1} B_{2}^{T} X_{\infty}$

$L=-B_{1} D_{21}^{*}-Y_{\infty} C_{2}^{T}\left(D_{21} D_{21}^{T}\right)^{-1}$

$Z=\left(I-Y_{\infty} X_{\infty}\right)^{-1}$

$D_{21}^{*}=D_{21}^{T}\left(D_{21} D_{21}^{T}\right)^{-1}$

$D_{12}^{*}=D_{12}^{T}\left(D_{12} D_{12}^{T}\right)^{-1}$

$\mathrm{Q}(\mathrm{s})$ is a free parameter.

To design $H-\infty$ controller based on the formula stated inEq.10 to Eq.12, first is to find the $H-\infty$ norm $\gamma$ to be calculated from Hamiltonian matrix represented in Eq.13 by conducting the iteration in the flow chart shown in Fig.6.

$H=\left[\begin{array}{cc}A & \frac{B B^{T}}{\gamma^{2}} \\ -C C^{T} & -A^{T}\end{array}\right]$

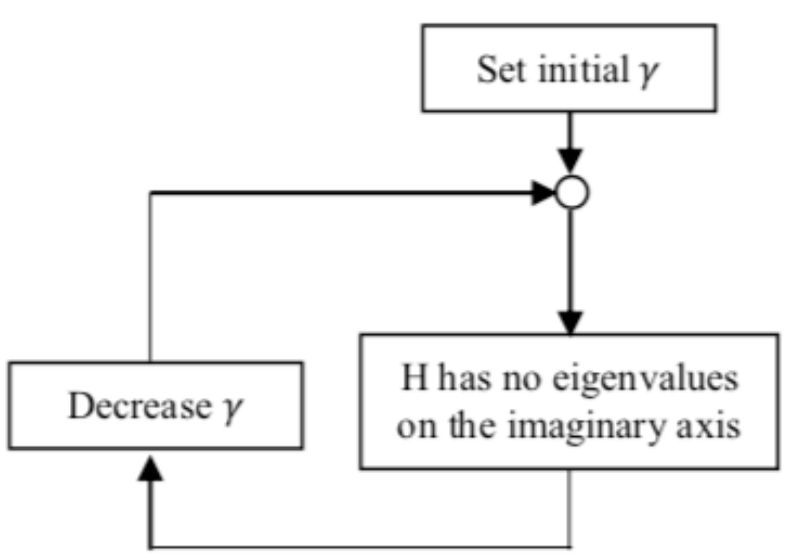

Fig.6. Calculating H- $\infty$ norm flow chart

Then solving the Algebraic Riccati Equations (AREs) presented in Eq.14 an Eq.15 to have the stabilizing solution for $X_{\infty} \geq 0$ and $Y_{\infty} \geq 0$ respectively[28].

$A^{T} X_{\infty}+X_{\infty} A+X_{\infty}\left(\gamma^{-2} B_{1} B_{1}^{T}-B_{2} B_{2}^{T}\right) X_{\infty}+C_{1}^{T} C_{1}=0$

$A Y_{\infty}+Y_{\infty} A^{T}+Y_{\infty}\left(\gamma^{-2} C_{1}^{T} C_{1}-C_{2}^{T} C_{2}\right) Y_{\infty}+B_{1} B_{1}^{T}=0$

$H-\infty$ controller designed based on the pervious explanation is written in Eq.16.

$$
K_{c}=\left[\begin{array}{cccccc}
0 & 1.915 & 1 & 0 & -1.915 & -3.059 \\
0 & -41.083 & 0 & 1 & 41.083 & -2.851 \\
-123.465 & 671.995 & -38.683 & -1.844 & -0.465 & 61.761 \\
123.465 & -1279.57 & 38.683 & 1.844 & -0.659 & -61.689 \\
-2 & -0.025 & -0.057 & -0.030 & 0 & 1 \\
0 & -1 & 0 & 0 & 1 & 0
\end{array}\right]
$$

\section{Performance Analysis}

Based on the step input signal, the system performance is analyzed in the form of percentage overshoot $(O S \%)$, rise time $\left(T_{r}\right)$, settling time $\left(T_{s}\right)$, and steady state error $\left(e_{s s}\right)[26]$. The system transient response and steady state error can be determined and analyzed as follows:

i. Rise time, $\left(T_{r}\right)$, the time required for the system response to go from the percentage of $10 \%$ to the percentage of $90 \%$ of its final value.

ii. Settling time, $\left(T_{s}\right)$, the time required for the system response to reach and stay within $\pm 2 \%$ of its final value.

iii. Overshoot, $(O S \%)$, the percentage of overshoot $O S \%$ is determined by Eq. 17 .

$$
\text { OS } \%=\frac{\text { Maximum Overshoot-Final Value }}{\text { Desired value }} \times 100 \%
$$


iv. Steady state error, $\left(e_{s s}\right)$, the difference between the steady state response and the desired output

Root mean square error (RMSE) is calculated in order to analyze the capability of the proposed controllers for the position tracking of the FLM system. The RMSE formula is presented in Eq.18. Where $r$ is the reference trajectory input, $y$ is the actual output position, and $n$ in the number of sample over a defined tracking process.

$R M S E=\sqrt{\frac{\sum_{i=1}^{n}\left(r_{i}-y_{i}\right)^{2}}{n}}$

The vibration suppression of the FLM system is evaluated based on two parameters, the amplitude of the largest peak oscillation and the time required to eliminate the vibration. The vibration is measured in the tip position of the FLM.

Design a robust controller for the position tracking and vibration suppression of the FLM system is the main aim of this study, so the robustness analysis of the proposed controllers that have been designed is an important matter in order to verify the robustness. The robustness evaluation in this study is by increasing the flexible link's length of the FLM system and by disturbing the system. The robustness evaluation of controllers is determined by measuring the robustness index (RI) for a reference trajectory (RT) under the system conditions over a tracking period $(\mathrm{T})$ as presented by Eq.19 which was derived in [29]. Where $\left(\mathrm{RMSE}_{\text {nom }}\right)$ is the root mean square error obtained from the nominal operating condition and $\left(\mathrm{RMSE}_{\mathrm{var}}\right)$ is the root mean square error obtained from the changed system.

$R I(T, R T)=\frac{\left|R M S E_{\text {nom }}-R M S E_{\mathrm{var}}\right|}{R M S E_{\text {nom }}}$

The robustness index will show the robustness of the proposed controllers once the FLM system has longer lengths or the system is disturbed.

\section{MATLAB Simulation and Results}

These results are simulated using MATLAB/Simulink in order to analyze the capability of $\mathrm{PD} / H-\infty$ integrated controller in terms of robustness and disturbance rejection compared to LQR controller. Both controllers are compared for their robustness and disturbance rejection by increasing the length of the FLM and by disturbing the system.

\subsection{Analysis of Robustness and Disturbance Rejection by Increasing the FLM's Length}

The used technique in this research in order to test the robustness of the $\mathrm{PD} / \mathrm{H}-\infty$ integrated controller is increasing the length of the FLM from the initial length of $50 \mathrm{~cm}$ to 75 $\mathrm{cm}$ and $100 \mathrm{~cm} .100 \mathrm{~cm}$ length of the FLM is long enough to test the robustness of the proposed controller.

\section{Analysis of the FLM System for $50 \mathrm{~cm}$}

The position tracking performance of the FLM system is plotted in Fig. 7 by the red color for the $\mathrm{PD} / H-\infty$ integrated controller and the blue color for the LQR controller. Based on the performance of both controllers and the analysis in Tab.3, the $\mathrm{PD} / H-\infty$ integrated controller response is faster than the LQR response and has less overshoot.

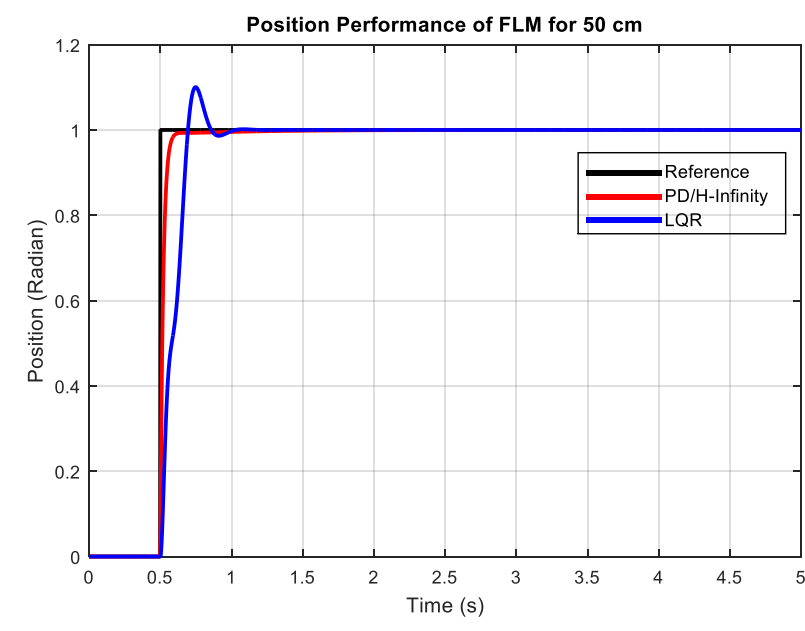

Fig.7. Position tracking of the FLM system for $50 \mathrm{~cm}$

Table 3. Transient response analysis for $50 \mathrm{~cm}$

\begin{tabular}{l|c|c|c|c}
\hline Controller & $\boldsymbol{T}_{\boldsymbol{r}}(\boldsymbol{s})$ & $\boldsymbol{T}_{\boldsymbol{s}}(\boldsymbol{s})$ & $\boldsymbol{O S}(\%)$ & $\boldsymbol{e}_{\boldsymbol{s} \boldsymbol{s}}(\mathbf{r a d})$ \\
\hline PD $/ \boldsymbol{H}-\infty$ & 0.045 & 0.083 & 0.00 & 0.00 \\
LQR & 0.156 & 0.332 & 10.04 & 0.00 \\
\hline
\end{tabular}

Even the $\mathrm{PD} / H-\infty$ integrated controller is faster for position tracking than the LQR controller, it has the capability to suppress the vibration of the FLM system much better than the LQR controller and reaches the stability in less time as shown in Fig. 8 and tabulated in Tab.4.

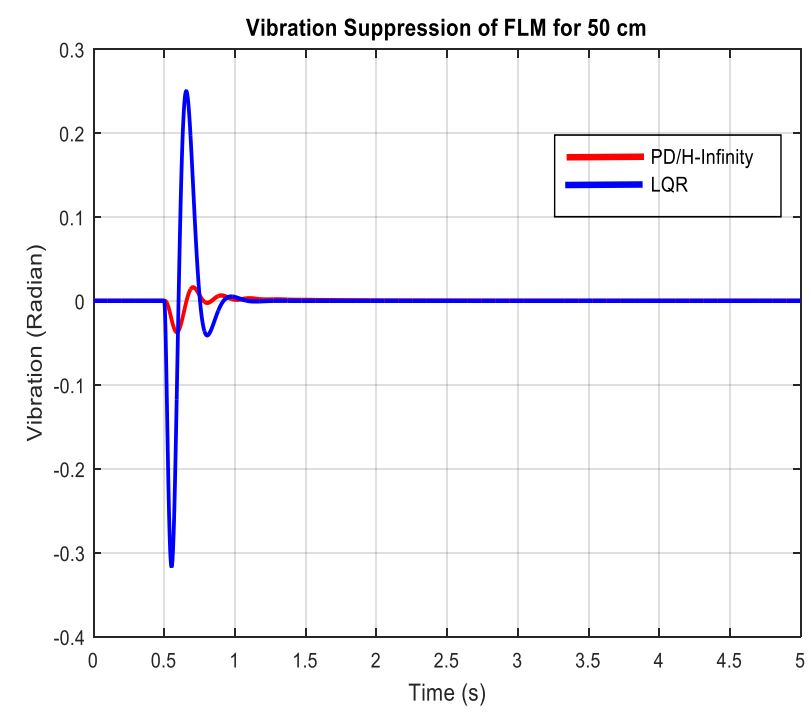

Fig.8. Vibration suppression of the FLM system for $50 \mathrm{~cm}$

Table 4. Vibration suppression analysis for $50 \mathrm{~cm}$

\begin{tabular}{l|c|c}
\multicolumn{1}{c|}{ Controller } & $\begin{array}{c}\text { Maximum Vibration } \\
\text { Peak to Peak (rad) }\end{array}$ & Stable Time (s) \\
\hline PD $/ \boldsymbol{H}-\infty$ & 0.053 & 0.5 \\
LQR & 0.566 & 0.6 \\
\hline
\end{tabular}

Analysis of the FLM System for $75 \mathrm{~cm}$

Increasing the length of the FLM system from $50 \mathrm{~cm}$ to 75 $\mathrm{cm}$ affects the performance of the LQR controller, but the $\mathrm{PD} / H-\infty$ integrated controller has the ability to track the 75 $\mathrm{cm}$ length without increasing the rise and settling time or the overshoot as well.Fig.9 and Tab.5 summarize the performance and the analysis of the position tracking of the FLM system for $75 \mathrm{~cm}$ respectively. 


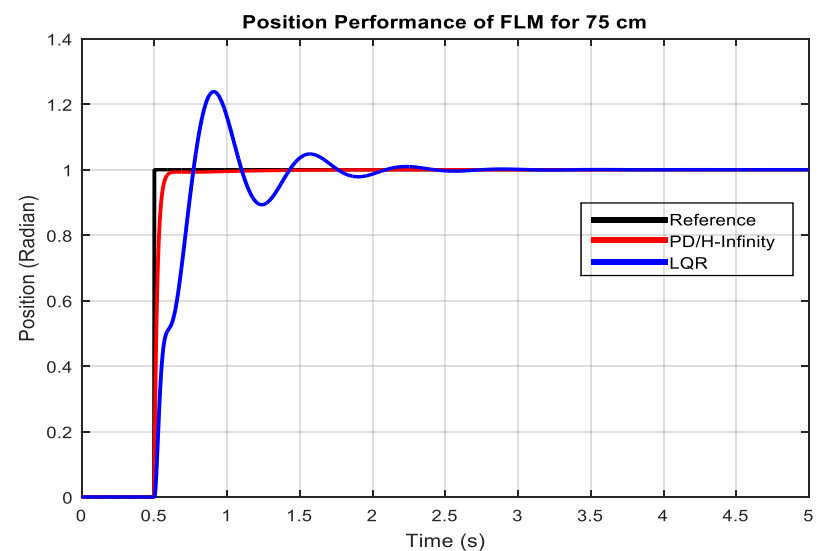

Fig.9. Position tracking of the FLM system for $75 \mathrm{~cm}$

Table 5. Transient response analysis for $75 \mathrm{~cm}$

\begin{tabular}{l|c|c|c|c}
\hline Controller & $\boldsymbol{T}_{\boldsymbol{r}}(\boldsymbol{s})$ & $\boldsymbol{T}_{\boldsymbol{s}}(\boldsymbol{s})$ & $\boldsymbol{O S}(\%)$ & $\boldsymbol{e}_{\boldsymbol{s s}}(\mathbf{r a d})$ \\
\hline PD $/ \boldsymbol{H}-\infty$ & 0.045 & 0.083 & 0.00 & 0.00 \\
LQR & 0.224 & 1.44 & 23.80 & 0.00 \\
\hline
\end{tabular}

The robustness index of the $\mathrm{PD} / H-\infty$ integrated controller once the length of the FLM system is $75 \mathrm{~cm}$ compared to the $50 \mathrm{~cm}$ initial length is zero and the LQR controller has the robustness index value of 0.1744 which means that the $\mathrm{PD} / H-\infty$ integrated controller is more robust than the LQR controller once the length of the FLM system increased to $75 \mathrm{~cm}$.

Table 6. Robustness analysis for $75 \mathrm{~cm}$

\begin{tabular}{l|c|c|c}
\hline \multirow{2}{*}{ Controller } & \multirow{2}{*}{ System } & \multicolumn{2}{|c}{ Controller System Analysis } \\
\cline { 3 - 4 } & & RMSE (rad) & $\begin{array}{c}\text { Robustness } \\
\text { Index }\end{array}$ \\
\hline $\mathbf{P D} / H-\infty$ & $l=50 \mathrm{~cm}$ & 0.0452 & 0 \\
& $l=75 \mathrm{~cm}$ & 0.0452 & 0.1061 \\
\hline $\mathbf{L Q R}$ & $l=50 \mathrm{~cm}$ & 0.1246 & 0.1744 \\
\hline
\end{tabular}

The vibration suppression for $75 \mathrm{~cm}$ length of the FLM system is shown in Fig.10. Based on the analysis, the PD/H$\infty$ integrated controller has only 0.069 radian maximum peak to peak deflection and can totally eliminate the vibration in one second while the LQR controller produces 0.68 radian maximum peak to peak vibration and takes two seconds to reach its stability as summarized in Tab.7. Overall, the $\mathrm{PD} / H-\infty$ integrated controller demonstrates much more effectiveness to suppress the vibration of the FLM system for $75 \mathrm{~cm}$ length.



Fig.10. Vibration suppression of the FLM system for $75 \mathrm{~cm}$
Table 7. Vibration suppression analysis for $75 \mathrm{~cm}$

\begin{tabular}{l|c|c}
\hline Controller & $\begin{array}{c}\text { Maximum Vibration } \\
\text { Peak to Peak (rad) }\end{array}$ & Stable Time (s) \\
\hline PD $/ \boldsymbol{H}-\infty$ & 0.069 & 1.00 \\
LQR & 0.680 & 2.00 \\
\hline
\end{tabular}

Analysis of the FLM System for $100 \mathrm{~cm}$

The response of the LQR controller presented in Fig.11 is unstable and has unsatisfied transient response performance which seems that the LQR controller can't track the length of $100 \mathrm{~cm}$ of the FLM system. However, the $\mathrm{PD} / H-\infty$ integrated controller has performance in terms of transient response and steady state error, this perfect performance confirms the robustness of the $\mathrm{PD} / H-\infty$ integrated controller and its ability to accurately track the $100 \mathrm{~cm}$ length of the FLM system.

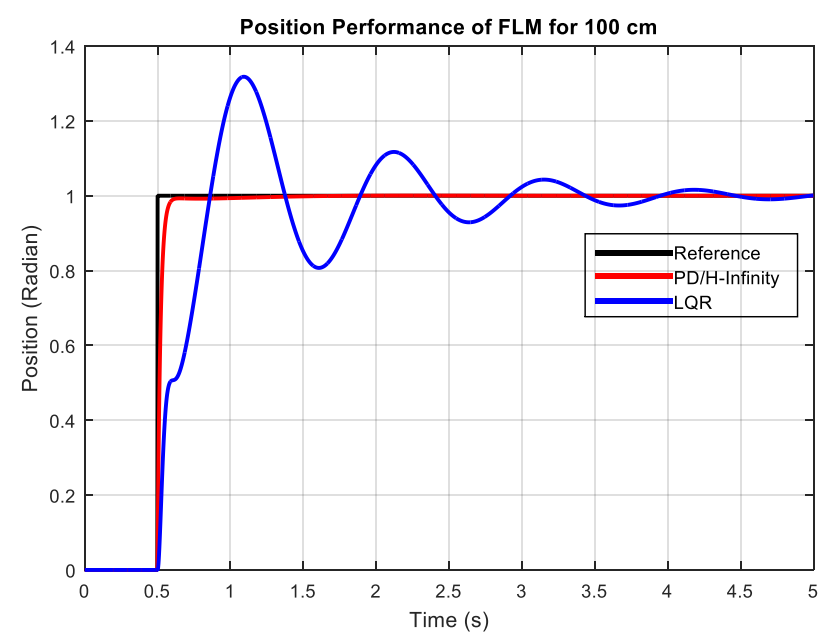

Fig.11. Position tracking of the FLM system for $100 \mathrm{~cm}$

Table 8. Transient response analysis for $100 \mathrm{~cm}$

\begin{tabular}{l|c|c|c|c}
\hline Controller & $\boldsymbol{T}_{\boldsymbol{r}}(\boldsymbol{s})$ & $\boldsymbol{T}_{\boldsymbol{s}}(\boldsymbol{s})$ & $\boldsymbol{O S}(\%)$ & $\boldsymbol{e}_{\boldsymbol{s s}}(\mathbf{r a d})$ \\
\hline $\mathbf{P D} / \boldsymbol{H}-\infty$ & 0.045 & 0.083 & 0.00 & 0.00 \\
$\mathbf{L Q R}$ & 0.304 & 3.283 & 31.80 & -- \\
\hline
\end{tabular}

Based on the robustness analysis, the LQR controller is not robust enough to track the FLM system with the length of $100 \mathrm{~cm}$ as the robustness index value is large and increases with increasing the length of the FLM system as tabulated in Tab.9. The robustness index value of the $\mathrm{PD} / \mathrm{H}$ $\infty$ integrated controller is the same value for the length of 50 $\mathrm{cm}, 75 \mathrm{~cm}$ and $100 \mathrm{~cm}$ which means that the controller has high robustness and can resist the negative effects caused by longer flexible links.

Table 9. Robustness analysis for $100 \mathrm{~cm}$

\begin{tabular}{l|c|c|c}
\hline \multirow{2}{*}{ Controller } & \multirow{2}{*}{ System } & \multicolumn{2}{|c}{ Controller System Analysis } \\
\cline { 3 - 4 } & & $\begin{array}{c}\text { RMSE } \\
(\mathbf{r a d})\end{array}$ & $\begin{array}{c}\text { Robustness } \\
\text { Index }\end{array}$ \\
\hline \multirow{2}{*}{$\mathbf{P D} / \mathrm{H}-\infty$} & $l=50 \mathrm{~cm}$ & 0.0452 & 0 \\
& $l=100 \mathrm{~cm}$ & 0.0452 & 0 \\
\hline \multirow{2}{*}{ LQR } & $l=50 \mathrm{~cm}$ & 0.1061 & 0.4552 \\
& $l=100 \mathrm{~cm}$ & 0.1544 & \\
\hline
\end{tabular}

The deflection caused by the length of $100 \mathrm{~cm}$ is so big once the LQR controller is employed as presented in Fig.12 does not eliminate the oscillations in short time, so the LQR controller fails to reduce the vibration of the FLM system with the length of $100 \mathrm{~cm}$. Meanwhile, the $\mathrm{PD} / H-\infty$ 
integrated controller suppresses the vibration of the $100 \mathrm{~cm}$ length effectively even that it takes long time to eliminate the deflection, but the deflection is still small as displayed in Tab.10 and Fig. 12.

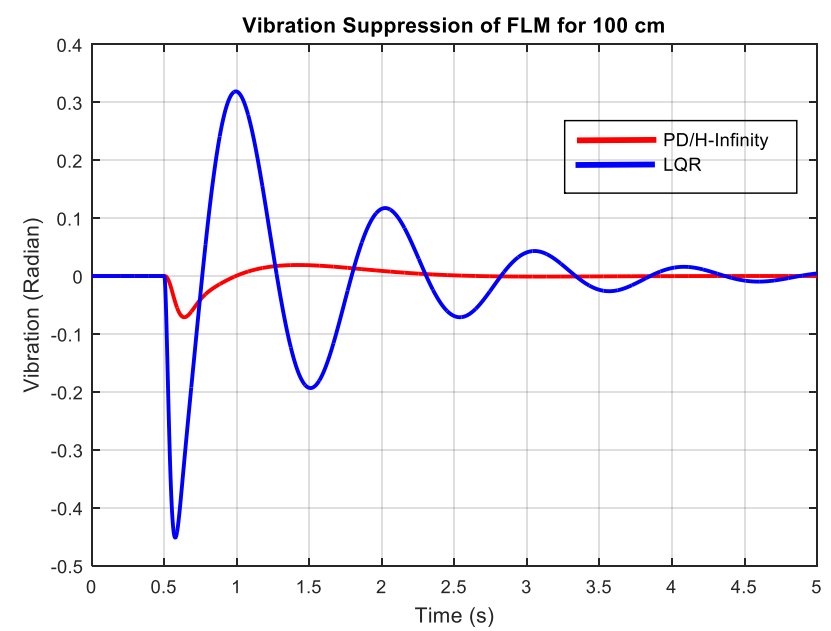

Fig.12. Vibration suppression of the FLM system for $100 \mathrm{~cm}$

Table 10. Vibration suppression analysis for $100 \mathrm{~cm}$

\begin{tabular}{l|c|c}
\hline Controller & $\begin{array}{c}\text { Maximum Vibration } \\
\text { Peak to Peak (rad) }\end{array}$ & Stable Time (s) \\
\hline PD $/ H-\infty$ & 0.09 & 1.9 \\
LQR & 0.769 & No Stable \\
\hline
\end{tabular}

\subsection{Analysis ofRobustness and Disturbance Rejection with a Disturbance}

Disturbance is unwanted input signal which affects the control system's output, and increases the system error. A robust controller should has the capability to eliminate the effects of disturbances on the output and the system error. The FLM system is disturbed by suddenly displacing the tip of the FLM 0.5 radian extra displacement of the final desired position using external force, the higher robust controller the better to keep the system position in its desired position and the faster to eliminate the vibration caused by the disturbance. The sudden and extra displacement of 0.5 radian is sufficient to test the robustness of the proposed controllers. The FLM system will be disturbed for all the lengths that have been used.

Analysis of the FLM System for $50 \mathrm{~cm}$ with the disturbance

The system is disturbed starting with the initial length of 50 $\mathrm{cm}$ for both controllers. The position tracking with the disturbance for $50 \mathrm{~cm}$ length is shown in Figure13. Based on Fig.13 and the classified data in Tab.11, the position tracking of the LQR controller is more affected once the FLM disturbed which means that the controller does not have good capability to resist external disturbances to the system and has the longer time to be resettled. However, the effect of the disturbance to the $\mathrm{PD} / H$ - $\infty$ integrated controller is very small and can be neglected.

Table 11. Effects analysis of the disturbance for $50 \mathrm{~cm}$

\begin{tabular}{l|c|c}
\hline Controller & $\begin{array}{c}\text { Maximum deflection } \\
\text { affected by a } \\
\text { disturbance (rad) }\end{array}$ & $\begin{array}{c}\text { Time to resettle } \\
\text { (s) }\end{array}$ \\
\hline PD $/ H-\infty$ & 0.004 & 0 \\
LQR & 0.5 & 0.303 \\
\hline
\end{tabular}

The zero value of the robustness index of the $\mathrm{PD} / H-\infty$ integrated controller indicates that the controller is robust enough to reject external disturbances for the length of 50 $\mathrm{cm}$ of the FLM system and does not affect the position tracking. The robustness index value of the LQR controller is larger as presented in Tab.12 which verifies the low robustness of the LQR controller.

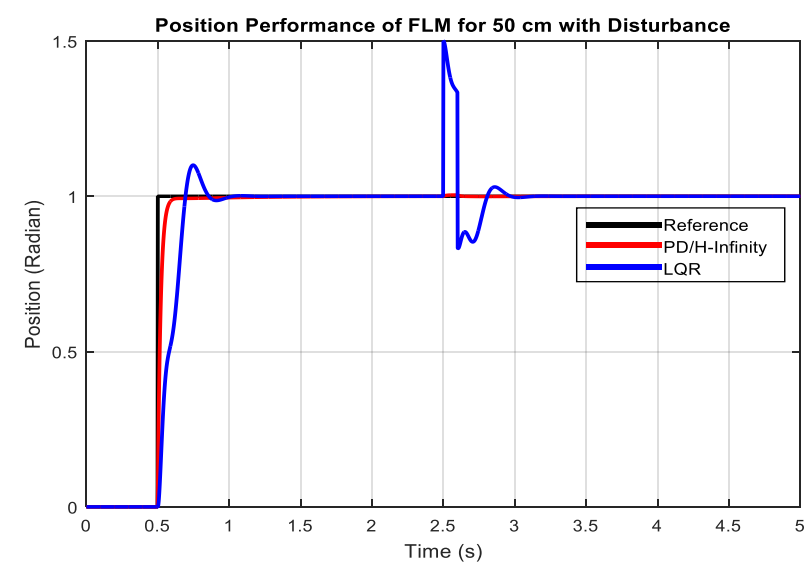

Fig. 13. Position tracking of the FLM system with the disturbance for $50 \mathrm{~cm}$

Table 12. Robustness analysis with the disturbance for 50 $\mathrm{cm}$

\begin{tabular}{|c|c|c|c|}
\hline \multirow[b]{2}{*}{ Controller } & \multirow[b]{2}{*}{ System } & \multicolumn{2}{|c|}{ Controller System Analysis } \\
\hline & & $\begin{array}{c}\text { RMSE } \\
\text { (rad) }\end{array}$ & $\begin{array}{c}\text { Robustness } \\
\text { Index }\end{array}$ \\
\hline $\mathrm{PD} / \mathrm{H}-\infty$ & $\begin{array}{c}\text { Without } \\
\text { disturbance } \\
\text { With } \\
\text { disturbance }\end{array}$ & $\begin{array}{l}0.0452 \\
0.0452\end{array}$ & 0 \\
\hline LQR & $\begin{array}{c}\text { Without } \\
\text { disturbance } \\
\text { With } \\
\text { disturbance }\end{array}$ & $\begin{array}{l}0.1061 \\
0.1229\end{array}$ & 0.1583 \\
\hline
\end{tabular}

The larger deflection caused by the disturbance is for the LQR controller, but the oscillation are eliminated in short time as shown in Fig. 14. However, the $\mathrm{PD} / H-\infty$ integrated controller resists the disturbance effects and effectively minimizes the vibration caused by the disturbance and reaches the stability in shorter time. Tab.13 shows the analysis of both controllers for $50 \mathrm{~cm}$ length with the disturbance.

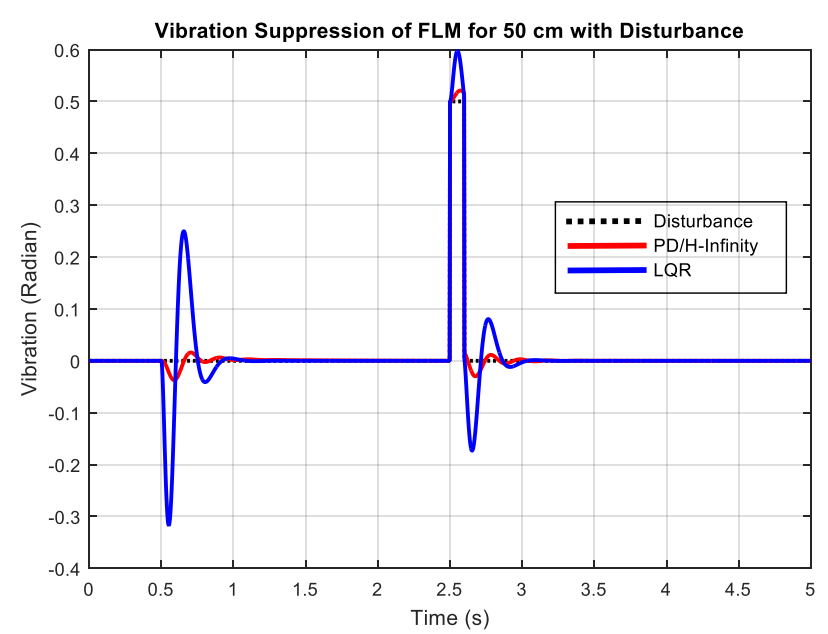

Fig.14. Vibration suppression of the FLM system with the disturbance for $50 \mathrm{~cm}$ 
Table 13. Vibration suppression analysis with the disturbance for $50 \mathrm{~cm}$

\begin{tabular}{l|c|c}
\hline Controller & $\begin{array}{c}\text { Largest deflection } \\
\text { (rad) }\end{array}$ & Stable time (s) \\
\hline PD $/ H-\infty$ & 0.029 & 0.5 \\
LQR & 0.1717 & 0.6 \\
\hline
\end{tabular}

Analysis of the FLM System for $75 \mathrm{~cm}$ with the disturbance

It is clearly observed that the position tracking of the LQR controller for $75 \mathrm{~cm}$ with the disturbance is largely affected and needs long time to be resettled, this indicates that the disturbance negatively affects the longer FLM more than the short FLM once the LQR controller is utilized as demonstrated in Fig.15. The disturbance effect to the $\mathrm{PD} / \mathrm{H}$ $\infty$ integrated controller performance for $75 \mathrm{~cm}$ length is the same as the effect once the length is $50 \mathrm{~cm}$ which verifies the high capability of this proposed controller to robustly track the FLM system even the system is disturbed or has longer FLMs.

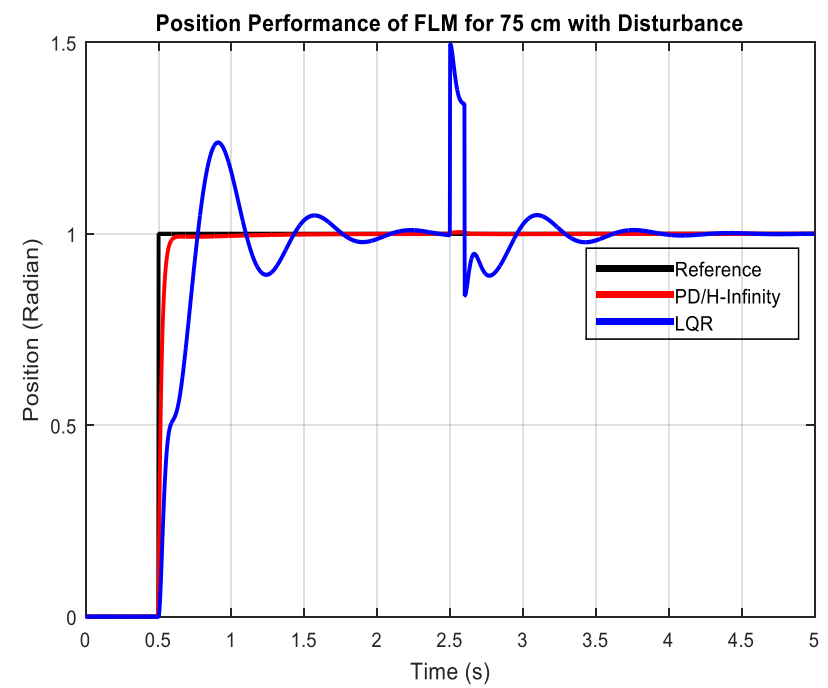

Fig.15. Position tracking of the FLM system with the disturbance for 75 $\mathrm{cm}$

Table 14. Effects analysis of the disturbance for $75 \mathrm{~cm}$

\begin{tabular}{l|c|c}
\hline Controller & $\begin{array}{c}\text { Maximum deflection } \\
\text { affected by a } \\
\text { disturbance (rad) }\end{array}$ & $\begin{array}{c}\text { Time to resettle } \\
\text { (s) }\end{array}$ \\
\hline PD $/ H-\infty$ & 0.0042 & 0 \\
LQR & 0.5 & 0.872 \\
\hline
\end{tabular}

The disturbance to the length of $75 \mathrm{~cm}$ is totally rejected by utilizing the $\mathrm{PD} / H$ - $\infty$ integrated controller as described in Tab.15 as the robustness index value is zero, but the LQR controller performance is affected by the disturbance and the deflection caused by the disturbance increases with increasing the length of the FLM system. In this case, the robustness index value of the LQR is smaller than its robustness index for the length of $50 \mathrm{~cm}$ because the disturbance comes against the original deflection which causes the reduction of the disturbance effects.

Table 15. Robustness analysis with the disturbance for 75 $\mathrm{cm}$

\begin{tabular}{l|c|c|c}
\hline \multirow{2}{*}{ Controller } & System & \multicolumn{2}{|c}{ Controller System Analysis } \\
\cline { 3 - 4 } & & $\begin{array}{c}\text { RMSE } \\
(\mathbf{r a d})\end{array}$ & $\begin{array}{c}\text { Robustness } \\
\text { Index }\end{array}$ \\
\hline $\mathrm{PD} / \boldsymbol{H}-\infty$ & Without & 0.0452 & 0 \\
\hline
\end{tabular}

\begin{tabular}{l|c|c|c}
\hline & $\begin{array}{c}\text { disturbance } \\
\text { With } \\
\text { disturbance }\end{array}$ & 0.0452 & \\
\hline LQR & $\begin{array}{c}\text { Without } \\
\text { disturbance } \\
\text { With } \\
\text { disturbance }\end{array}$ & 0.1246 & 0.1156 \\
\hline
\end{tabular}

The vibration suppression of the FLM system with the disturbance for the length of $75 \mathrm{~cm}$ is presented in Fig. 16 and the analysis data is classified in Tab.16. Based on that, the $\mathrm{PD} / H-\infty$ integrated controller still demonstrates better capability to reject the disturbance and to suppress the vibration. The oscillation of the FLM system resulted by the disturbance for the $75 \mathrm{~cm}$ has smaller peak than the oscillation caused by the disturbance for the $50 \mathrm{~cm}$ length once the LQR controller is employed because the disturbance is partially rejected by the original oscillation, but the controller takes longer time to eliminate the oscillation of the $75 \mathrm{~cm}$ length.

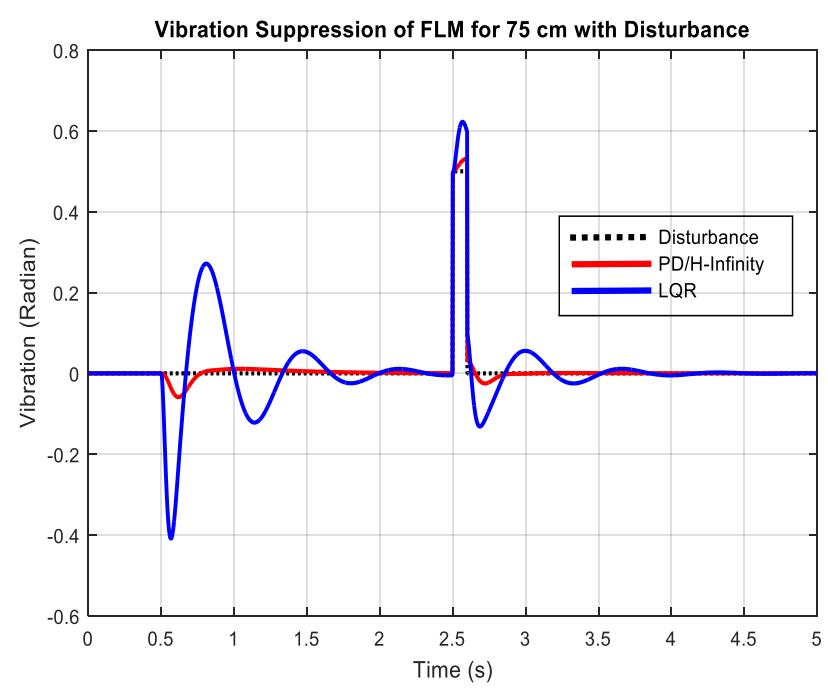

Fig.16. Vibration suppression of the FLM system with the disturbance for $75 \mathrm{~cm}$

Table 16. Vibration suppression with the disturbance for 75 $\mathrm{cm}$

\begin{tabular}{l|c|c}
\hline Controller & $\begin{array}{c}\text { Largest deflection } \\
\text { (rad) }\end{array}$ & Stable time (s) \\
\hline PD/H- $\infty$ & 0.0250 & 0.3 \\
LQR & 0.1315 & 1.4 \\
\hline
\end{tabular}

Analysis ofthe FLM System for $100 \mathrm{~cm}$ with the disturbance

The position tracking reponse of the LQR controller and the $\mathrm{PD} / H-\infty$ integrated controller for $100 \mathrm{~cm}$ length with the disturbance of the FLM system is presented in Fig.17. The position tracking of the $\mathrm{PD} / H-\infty$ integrated controller for 100 $\mathrm{cm}$ is not much affected compared to the $50 \mathrm{~cm}$ and $75 \mathrm{~cm}$ length which means that the controller can robustly track the FLM system with $100 \mathrm{~cm}$ length and can reject the external disturbance. However, the LQR controller is not suitable to track the length of $100 \mathrm{~cm}$ with the disturbance as the controller is unstable and its position tracking is largely influenced by the disturbance. 


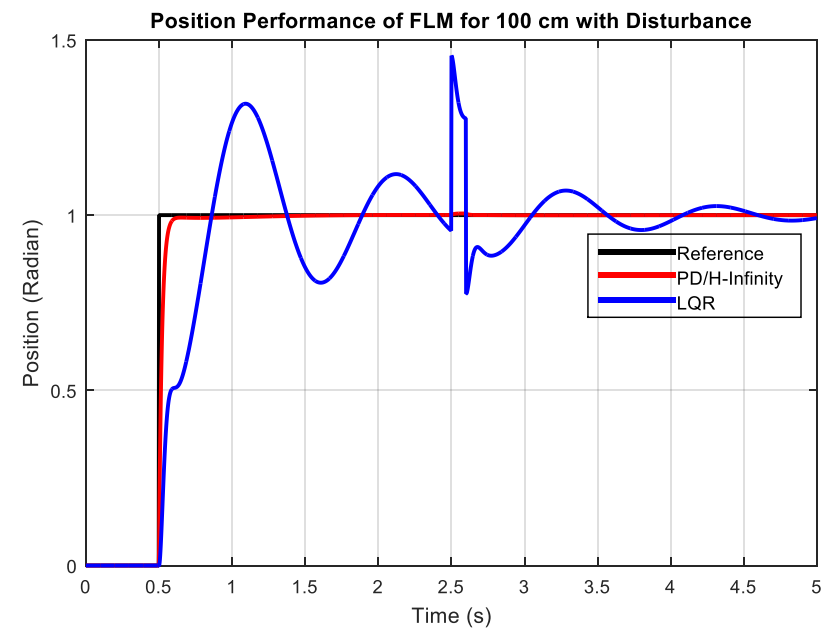

Fig.17. Position tracking of the FLM system with the disturbance for $100 \mathrm{~cm}$

Table 17. Effects analysis of the disturbance for $100 \mathrm{~cm}$

\begin{tabular}{l|c|c}
\hline Controller & $\begin{array}{c}\text { Maximum deflection } \\
\text { affected by a } \\
\text { disturbance (rad) }\end{array}$ & $\begin{array}{c}\text { Time to resettle } \\
\text { (s) }\end{array}$ \\
\hline PD $/ H-\infty$ & 0.0046 & 0 \\
LQR & 0.4545 & Not stable \\
\hline
\end{tabular}

The $\mathrm{PD} / H-\infty$ integrated controller is robust enough for position tracking of the FLM system for the length of 100 $\mathrm{cm}$ with the disturbance as its robustness index value is zero which means that the controller can totally rejection the disturbance. The LQR controller has larger value of the robustness index than the $\mathrm{PD} / H-\infty$ integrated controller, but smaller values of the robustness index than its own values for the lengths of $50 \mathrm{~cm}$ and $75 \mathrm{~cm}$ because the disturbance occurs against the original deflection and once the original deflection is larger can reject larger amount of the disturbance, but the system remains oscillated for longer time.

Table 18. Robustness analysis with the disturbance for 100 $\mathrm{cm}$

\begin{tabular}{|c|c|c|c|}
\hline \multirow[b]{2}{*}{ Controller } & \multirow[b]{2}{*}{ System } & \multicolumn{2}{|c|}{ Controller System Analysis } \\
\hline & & RMSE (rad) & $\begin{array}{l}\text { Robustness } \\
\text { Index }\end{array}$ \\
\hline $\mathbf{P D} / H-\infty$ & $\begin{array}{c}\text { Without } \\
\text { disturbance } \\
\text { With } \\
\text { disturbance } \\
\end{array}$ & $\begin{array}{l}0.0452 \\
0.0452\end{array}$ & 0 \\
\hline LQR & $\begin{array}{c}\text { Without } \\
\text { disturbance } \\
\text { With } \\
\text { disturbance } \\
\end{array}$ & $\begin{array}{l}0.1544 \\
0.1648\end{array}$ & 0.0674 \\
\hline
\end{tabular}

Based on Fig.18 and Tab.19, the $\mathrm{PD} / H-\infty$ integrated controller can suppress the vibration caused by the disturbance in 0.4 seconds which is short time and this proves the capability of the controller to suppress the vibration of the FLM system with the disturbance for 100 cm length. The LQR controller does not have the ability to quickly minimize the FLM system vibration once its length is $100 \mathrm{~cm}$ and is disturbed.

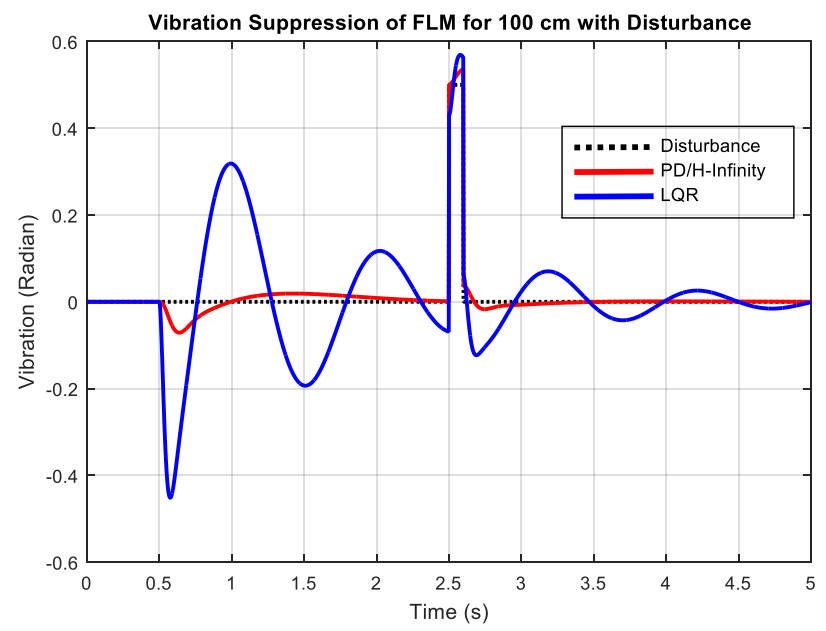

Fig.18. Vibration suppression of the FLM system with the disturbance for $100 \mathrm{~cm}$

Table 19. Vibration suppression with the disturbance for $100 \mathrm{~cm}$

\begin{tabular}{l|c|c}
\hline Controller & $\begin{array}{c}\text { Largest deflection } \\
\text { (rad) }\end{array}$ & Stable time (s) \\
\hline PD $/ H-\infty$ & 0.0171 & 0.4 \\
LQR & 0.1231 & Not stable \\
\hline
\end{tabular}

\section{Conclusion}

This research starts with the introduction to review the previous control methods that have been used for the purpose of position tracking and vibration suppression of the FLM system. In this research, a novel $\mathrm{PD} / H-\infty$ integrated controller is designed for position tracking and vibration suppression as a robust controller for the FLM system. The proposed $\mathrm{PD} / H-\infty$ integrated controller is a robust controller which has verified for its robustness in terms of controlling longer links and disturbance rejection.

The $\mathrm{PD} / H-\infty$ integrated controller has demonstrated high robustness either for tracking longer lengths of the FLM system and suppress their vibration or to reject disturbances to the FLM system compared to the LQR controller. The $\mathrm{PD} / H-\infty$ integrated controller could robustly track the length of $100 \mathrm{~cm}$ which is long enough in robotics uses and suppress its vibration even the system was disturbed. However, the performance of the LQR controller is unstable for the length of $100 \mathrm{~cm}$ and couldn't reduce its vibration in both cases of disturbance presence and absence. These proposed controllers have been simulated and validated via MATLAB/Simulink software. However, the experimental work is more reliable validation and will efficiently examine the effectiveness and the robustness of the $\mathrm{PD} / H-\infty$ integrated controller for position tracking and vibration suppression of lengths uncertainties and at the presence of disturbances.

\section{Acknowledgment}

The authors would like to express their thanks to Universiti Teknikal Malaysia Melaka (UTeM) for supporting this research. This research has been conducted in Center for Robotics and Industrial Automation (CeRIA).

This is an Open Access article distributed under the terms of the Creative Commons Attribution License 


\section{References}

1. R. Dixit and R. P. Kumar, "Working and Limitations of Cable Stiffening in Flexible Link Manipulators," Adv. Acoust. Vib., vol. 2016, pp. 1-9, 2016.

2. H. Geniele, R. V Patel, and K. Khorasani, "End-Point Control of a Flexible-Link Manipulator: Theory and Experiments," IEEE Trans. Control Syst. Technol., vol. 5, no. 6, pp. 556-570, 1997.

3. M. Khairudin, Z. Mohamed, and A. R. Husain, "Dynamic Model and Robust Control of Flexible Link Robot Manipulator," Telkomnika, vol. 9, no. 2, pp. 279-287, 2011.

4. F. Raouf, S. Mohamad, S. Maarouf, and B. Maamar, "Distributed adaptive control strategy for flexible link manipulators," Robotica, vol. 33, no. 4, pp. 768-786, 2016.

5. S. Suklabaidya, K. Lochan, and B. K. Roy, "Control of rotational base single link flexible manipulator using different SMC techniques for variable payloads," Proc. IEEE Int. Conf. Energy, Power Environ. Towar. Sustain. Growth, ICEPE, Shillong, India, pp. 1-6, 2015.

6. A. Shawky, D. Zydek, Y. Z. Elhalwagy, and A. Ordys, "Modeling and nonlinear control of a flexible-link manipulator," Appl. Math Model., vol. 37, no. 23, pp. 9591-9602, 2013.

7. A. San-Millan, V. Feliu, and A. Garcia, "A two-stage contro scheme of single-link flexible manipulators," Proc. IEEE 23rd Mediterr. Conf. Control Autom. MED, pp. 1098-1105, 2015.

8. G. Neugschwandtner, M. Reekmans, and D. Van Der Linden, "An open automation architecture for flexible manufacturing," Proc. IEEE 18th Conf. Emerg. Technol. Fact. Autom., pp. 1-5, 2013.

9. R. J. Theodore and A. Ghosal, "Robust control of multilink flexible manipulators," Mech. Mach. Theory, vol. 38, pp. 367-377, 2003.

10. A. Abe, "Trajectory planning for residual vibration suppression of a two-link rigid-flexible manipulator considering large deformation,' Mech. Mach. Theory, vol. 44, pp. 1627-1639, 2009.

11. K. Springer, H. Gattringer, and P. Staufer, "On time-optimal trajectory planning for a flexible link robot," Proc IMechE Part I: J Systems and Control Engineering, 2013, vol. 227, no. 10, pp. 752763.

12. M. Benosman, G. Le Vey, L. Lanari, and A. De Luca, "Rest-to-Rest Motion for Planar Multi-Link Flexible Manipulator Through Backward Recursion," J. Dyn. Syst. Meas. Control, 126(1), pp. $115-123,2004$

13. Z. Jiang, "Impedance Control of Flexible Robot Arms with Parametric Uncertainties," J. Intell. Robot. Syst., vol. 42, pp. 113 133, 2005.

14. V. P. Phan, N. S. Goo, and H. C. Park, "Vibration Suppression of a Flexible Robot Manipulator with a Lightweight Piezo-composite Actuator," Int. J. Control. Autom. Syst., vol. 7, no. 2, pp. 243-251, 2009

15. B. Subudhi, S. Ranasingh, and A. K. Swain, "Evolutionary computation approaches to tip position controller design for a twolink flexible manipulator," Arch. Control Sci., vol. 21, no. 3, pp.
269-285, 2011

16. M. S. Alam and M. O. Tokhi, "Hybrid fuzzy logic control with genetic optimisation for a single-link flexible manipulator," Eng. Appl. Artif. Intell., vol. 21, no. 6, pp. 858-873, 2008.

17. J. R. Forbes and C. J. Damaren, "Design of Gain-Scheduled Strictly Positive Real Controllers Using Numerical Optimization for Flexible Robotic Systems," J. Dyn. Syst. Meas. Control, vol. 132, pp. 1-7, 2013.

18. M. Hassan, R. Dubay, C. Li, and R. Wang, "Active vibration control of a flexible one-link manipulator using a multivariable predictive controller," Elsevier on Mechatronics, vol. 17, no. 6, pp. 311-323, 2007.

19. M. Sayahkarajy and Z. Mohamed, "Mixed sensitivity $\mathrm{H} 2 / \mathrm{H} \infty$ control of a flexible-link robotic arm," Int. J. Mech. Mechatronics Eng., vol. 14, no. 1, pp. 21-27, 2014.

20. A. M. Abdullahi, Z. Mohamed, M. Muhammad, and A. A. Bature, "Vibration and Tip Deflection Control of A Single - Link Flexible Manipulator," Int. J. Instrum. Control Syst., vol. 3, no. 4, pp. 17-27, 2013.

21. D. Sun, J. K. Mills, J. Shan, and S. K. Tso, “A PZT actuator control of a single-link flexible manipulator based on linear velocity feedback and actuator placement," Mechatronics, vol. 14, no. 4, pp. 381-401, 2004

22. K. Gurses, B. J. Buckham, and E. J. Park, "Vibration control of a single-link flexible manipulator using an array of fiber optic curvature sensors and PZT actuators," Mechatronics, vol. 19, no. 2, pp. 167-177, 2009 .

23. E. A. Alandoli, M. Sulaiman, and M. Rashid, "A Review Study on Flexible Link Manipulators," J. Telecommun. Electron. Comput. Eng. Fig., vol. 8, no. 2, pp. 93-97, 2016.

24. E. V. Kumar, J. Jerome, and K. Srikanth, "Algebraic approach for selecting the weighting matrices of linear quadratic regulator,' Proceeding IEEE Int. Conf. Green Comput. Commun. Electr. Eng., pp. 1-6, 2014.

25. E. A. Alandoli, M. Z. A. Rashid, and M. Sulaiman, "A comparison of PID and LQR controllers for position tracking and vibration suppression of flexible link manipulator," J. Theor. Appl. Inf. Technol., vol. 95, no. 13, pp. 2949-2955, 2017.

26. N. S. Nise, Control Systems Engineering, Sixth edit. John Wiley \& Sons, 2011

27. E. Rijanto, Robust Control Theory for Application from $\mathrm{H} 2$ to mixed $H 2 / H-\infty$ control, First edition. ITB Press Bandung, 2000

28. E. Frazzoli, "Dynamic Systems and Control: Ho Synthesis," Aeronaut. Astronaut. Massachusetts Inst. Technol., pp. 1-12, 2011.

29. A. Bonchis, P. I. Corke, and D. C. Rye, "Experimental Evaluation of Position Control Methods for Hydraulic Systems," IEEE Trans. Control Syst. Technol., vol. 10, no. 6, pp. 876-882, 2002. 